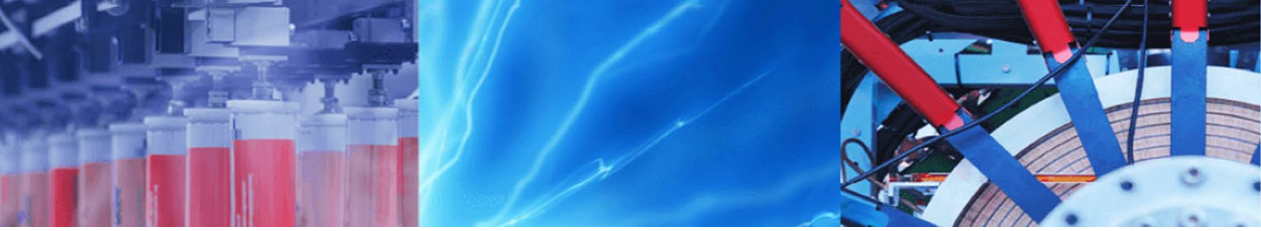

Research Article

\title{
Investigation of wind speed characteristics and its energy potential in Makurdi, north central, Nigeria
}

\author{
Moses Owoicho Audu' ${ }^{10} \cdot$ Agba Sixtus Terwase $^{1} \cdot$ Bernadette C. Isikwue $^{1}$
}

(c) Springer Nature Switzerland AG 2019

\begin{abstract}
This study investigates wind speed characteristics and its energy potential in Makurdi, in order to assess the prospect and availability of wind energy for electricity generation in the region. Wind speed data measured at $10 \mathrm{~m}$ were obtained from the Nigeria Meteorology Agency, Lagos. The data spanned from 1961-2014. Weibull distribution function was employed to determine wind energy potential in Makurdi. Results reveal that the period of highest potential for wind harvest was the peak of dry season (i.e. April) and that for lowest yield was the onset of dry season (i.e. November). Wind speed characteristics used for wind energy estimate was determined. Furthermore, high values of Weibull shape and scale parameters obtained in this study indicate the availability of wind speed and the windy nature of Makurdi. The wind power density of $86.85 \mathrm{~W} / \mathrm{m}^{2}$ suggests that Makurdi wind can be used for electricity generation. Besides, monthly and annual mean wind speeds were above the minimum values $(3.0-4.0 \mathrm{~m} / \mathrm{s})$ required for most wind turbines to operate. The wind profile and its characteristics depict Makurdi as a suitable site for wind power generation. Hence, there is huge prospect of wind power generation in Makurdi and its environs.
\end{abstract}

Keywords Wind speed characteristic · Weibull distribution function · Weibull parameters · Renewable energy · Wind power - Nigeria

\section{Introduction}

Power deficit and epileptic power supply is a setback to socio-economic development of any economy as is evident in Nigeria. Despite the abundant energy resources in the country, there is persistent electricity supply deficit, which may be attributed to underutilization of these abundant natural resources [1].

The population of Nigeria is on the increase, leading to high demand for energy. There is every need for energy diversification as the country is blessed with abundant renewable energy sources ranging from solar power, hydropower to wind power. The country has an estimated moderate wind energy prospect, which of course has not been connected to the existing grid to meet with the demands for energy consumption [2].
Nigeria's energy is supplied mainly from hydropower and thermal power stations. Due to the country's location, it experiences two major seasons (wet and dry seasons). This seasonality affects water availability at the hydropower stations resulting in epileptic power supply during low water levels. Also, the thermal stations, have been greatly affected by lack of adequate supplies of natural gas; thereby making continuous production from these installations difficult [3].

Worst still is the environmental impacts due to the emission of greenhouse gases into the atmosphere from the use of conventional sources; thereby causing global warming leading to climate change [4]. Hence, studying and harnessing renewable sources such as wind, solar, etc. are becoming valuable resources around the world.

Moses Owoicho Audu, audumoses53@yahoo.com | ${ }^{1}$ Department of Physics, Federal University of Agriculture, P.M.B. 2372, Makurdi, Benue State, Nigeria.

SN Applied Sciences (2019) 1:178 | https://doi.org/10.1007/s42452-019-0189-x 
Wind energy by nature is clean, abundant, affordable, inexhaustible and environmentally preferable unlike fossil fuels [5]. Due to its numerous advantages, wind energy has become the fastest growing renewable sources of energy in both developed and developing countries [6]. The energy produced by windmills and wind turbines can be used in grinding grains, pumping water, sawing wood, hammering seeds, and generating electricity, depending on the capacity.

Several research works have been carried out both within and outside Nigeria to investigate the prospect of wind energy potential; which can be used as alternative energy resources (e.g. [7-10]). Oyedepo and Adaramola [6], reported that the annual mean wind speed for Enugu, Owerri and Onitsha were 5.42, 3.36 and $3.59 \mathrm{~m} / \mathrm{s}$ respectively with an annual mean power densities of $96.98,23.23$ and $28.34 \mathrm{~W} / \mathrm{m}^{2}$ respectively. They also noted that the annual mean values of the most probable wind speed for Enugu, Owerri and Onitsha were 5.47, 3.72 and $3.50 \mathrm{~m} / \mathrm{s}$ respectively, while the annual values of the wind speed carrying maximum energy were $6.48,4.33$ and $3.90 \mathrm{~m} / \mathrm{s}$ respectively. Similarly, [4] reported the annual wind speed of $1.3 \mathrm{~m} / \mathrm{s}$ and wind power density of $3.11 \mathrm{~W} / \mathrm{m}^{2}$ for Calabar. They concluded that Calabar has a low wind speed regime.

Working on wind energy potential in Nigeria, [11] noted that electricity production from wind power has not been connected to the existing grid. They concluded by given information about the wind speed potential in Nigeria, the conditions necessary for wind generator to be connected to the existing grid and how to carry out the connection. Similarly, [3] reported the numerous challenges facing wind energy development in Nigeria. They therefore, suggested the possible strategies that will encourage wind energy technology in the country.

It has been reported that the north, middle belt and south eastern regions of Nigeria have great potential for wind energy. The mean wind speed was reported to range from 3.0 to $3.5 \mathrm{~m} / \mathrm{s}$ in the southern region and $4.0-7.5 \mathrm{~m} / \mathrm{s}$ in the northern region. Due to the hilly nature of the northern region, wind speed may be up to $8.70 \mathrm{~m} / \mathrm{s}$ [3]. Similarly, [12] reported that the south western region of Nigeria particularly Lagos and Oyo States have potentials for wind energy with mean wind speeds of 2.9 and $5.8 \mathrm{~m} / \mathrm{s}$ respectively.

Most of the research works on wind energy potential in Nigeria were carried out in the coastal area [4], south eastern region $[6,13,14]$, south western region $[11,15]$, north eastern region [16], north western region $[2,12$, 17] with very few works in north central region of Nigeria $[18,19]$. Much work on wind energy potential have not be carried out in the north central region of Nigeria particularly in Makurdi Benue State. Hence, this study hopes to investigate wind energy potential in Makurdi which can serve as an alternative energy to the epileptic power supply in the state.

This study hopes to contribute to the already existing wind resources assessment for the development of wind energy technology (WET) in Nigeria. It will also help in understanding wind regimes and prospects in Makurdi by carrying out wind speed analysis which is a major factor in determining wind energy power for any given location.

Benue State is one of the thirty-six states in Nigeria. It is the eight (8) poorest states in the country. Poverty in the state is even on the increase in the last decades due to corruption, communal crisis, herdsmen killing, etc. [20]. Makurdi, the capital of Benue State, is located at latitude $7^{\circ} 43^{\prime} 5^{\prime \prime} \mathrm{N}$ and longitude $8^{\circ} 32^{\prime} 10^{\prime \prime} \mathrm{E}$. Makurdi and its environs are relatively hot due to the present of River Benue which serves as heat sink. High temperatures are experienced especially in March and April with daily mean temperature of about $36^{\circ} \mathrm{C}$. Average daily temperatures are as high as $32^{\circ} \mathrm{C}$ and rarely fall below $20^{\circ} \mathrm{C}$ [21]. Makurdi has its windiest period in spring (March, April and May) and its most calm period in autumn (September, October and November), recording monthly wind speeds ranging from 1.3 to $9.2 \mathrm{~m} / \mathrm{s}$ [22].

Benue State is popularly known as the food basket of the nation, since agriculture is an important sector in the overall economy. Subsistence farming is widely practiced in the state by about $80 \%$ of the total population. However, food insecurity, hunger and poverty are some of the major challenges in the state. This is attributed majorly to lack of storage and processing facilities due to epileptic power supply. Therefore, there is need to assess alternate power supply such as wind energy. Many researchers have shown that before the installation of wind turbines in any site for power/electricity, it is very important to investigate wind energy potential of the area. Hence, this study investigates wind speed characteristics and its energy potential in Makurdi, Nigeria.

\section{Materials and methods}

Monthly mean daily wind speed data for Makurdi, measured at $10 \mathrm{~m}$ by a cup-generator anemometer was obtained from the Nigeria Meteorology (NIMET) Agency Oshodi, Lagos. The data spanned for 54 years (1961-2014). The data were used to estimate wind energy potential in Makurdi.

Different mathematical models (such as normal and lognormal) and statistical methods (such as Weibull and Reyleigh distribution models) have been used in analyzing wind data. However, the two-parameter Weibull probability distribution function is more acceptable than other 
statistical functions since it gives better fit for wind distribution [5]. Several researchers have carried out statistical analysis of wind characteristics using weibull parameters (e.g. [7, 23-25]).

Weibull distribution model was employed in analyzing the wind data used in this study. From Weibull distribution, the probability density function and the corresponding cumulative distribution functions are used to characterize variations of wind velocity. It is worthy of note that the probability density function, $f(V)$ give the probability of the wind at a given velocity, $V$. On the other hand, the corresponding cumulative distribution function, $F(V)$ of the velocity, $V$ indicates the probability that the wind velocity is greater than or less than $V$, or within the given wind speed range [6]. The Weibull probability density function $f(V)$ is expressed as $[2,6]$ :

$f(V)=\left(\frac{k}{c}\right)\left(\frac{V}{c}\right)^{k-1} \exp \left[-\left(\frac{V}{c}\right)^{k}\right]$

where $k$ is a dimensionless Weibull shape parameter, $c$ is the Weibull scale parameter $(\mathrm{m} / \mathrm{s}), V$ is the wind speed $(\mathrm{m} / \mathrm{s})$.

The cumulative distribution function, $F(V)$ which is the integral of the probability density function is given as $[2$, 6]:

$F(V)=1-\exp -\left(\frac{V}{c}\right)^{k}$

The following parameters were computed using expressions as adapted from different authors:

1. The Weibull shape parameter, $\mathrm{k}$ was calculated using Eqs. 3 [4]:

$$
k=\left(\frac{\sigma}{V_{m}}\right)^{-1.086}
$$

where $\sigma$ is standard deviation

2. The Weibull scale parameter, $c$ was computed using the expression [6]:

$c=\frac{V_{m} k^{2.6674}}{0.184+0.816 k^{2.73855}}$

where $V_{m}$ is the mean wind speed.

3. The most probable wind speed, $V_{F}$ was obtained from Eq. 5 [15].

$V_{F}=c\left(\frac{\mathrm{k}-1}{k}\right)^{\frac{1}{k}}$

4. The wind speed carrying maximum energy, $V_{E}$ was computed using [15]:
$V_{E}=c\left(\frac{\mathrm{k}+2}{k}\right)^{\frac{1}{k}}$

Using Weibull probability density function, wind power density, $P_{D}$ (wind power per unit area) was computed from Eq. 7 [2].

$P_{D}=\frac{P(V)}{A}=\frac{1}{2} \rho c^{3} \Gamma\left(1+\frac{3}{k}\right)$

where $P(V)$ is the wind power (W), $\rho$ is the air density at the site (typically $1.225 \mathrm{~kg} / \mathrm{m}^{3}$ ), $\Gamma$ is the gamma function.

5. The mean energy density $\left(E_{D}\right)$ over a given period of time, $T$ was obtained using the expression [6]:

$$
E_{D}=\frac{1}{2} \rho c^{3} \Gamma\left(1+\frac{3}{k}\right) T
$$

\section{Results and discussions}

It could be observed from the monthly variation of wind speed (Fig. 1) that the maximum wind speed of $5.87 \mathrm{~ms}^{-1}$ was observed in April. This may be attributed to changes in the pressure gradient caused by temperature differentials due to the differential solar heating of the Earth's surface [21]. April is the transition period from dry to rainy season when the sky is free from harmattan dust and cloud activities. High solar radiation reaches the Earth's surface during this period, leading to high temperature, and hence high wind speed. This is due to the fact that wind energy is a form of converted solar energy, resulting from the uneven heating of the Earth's surface by the Sun [4].

On the other hand, the lowest wind speed of $3.51 \mathrm{~ms}^{-1}$ was observed in November; the onset of dry season when the sky is relatively loaded with harmattan dust. Most of the incoming solar radiation is scattered and some

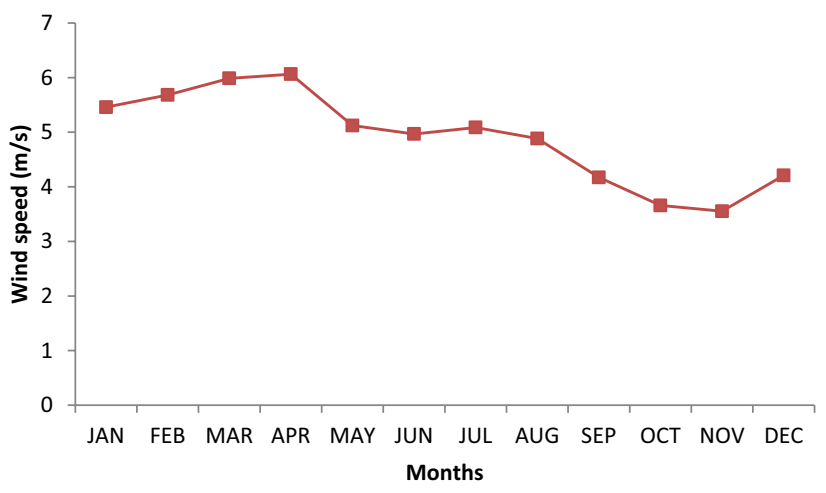

Fig. 1 Monthly mean daily wind speed variations in Makurdi (1961-2014) 
reflected into space, hence low temperature. This leads to low wind speed during this period. This result is in agreement with the work of $[3,12]$ who noted that maximum wind speed in Nigeria occurs between April and August while minimum wind speed occurs between September and November. Consequently, maximum power production from wind power system in Makurdi can be observed at the peak of dry season (i.e. April), while minimum power can be obtained at the onset of dry season (i.e. November).

The annual mean wind speed for the period under investigation (1961-2014) was $4.77 \mathrm{~ms}^{-1}$ (Table 1). This implies that Makurdi is a moderate wind speed region. It is interesting to note that wind speed is within the range values $\left(2.2-10.1 \mathrm{~ms}^{-1}\right)$ reported for middle belt region of Nigeria [19]. According to [11], values of most wind turbines start generating electricity at wind speed of about $3.0-4.0 \mathrm{~m} / \mathrm{s}$. The monthly and annual mean wind speed obtained in this work, therefore, implies that Makurdi and its environs have great potential for wind power generation.

The variation trends of wind speed from 1961 to 2014 using Mann-Kendall trend test is shown in Fig. 2. Increasing positive trend was observed in the variation trends of wind speed. This was significance at 0.05 level. This depicts increase in wind speed which may probably be due to climate change. [12] noted that time, season and duration of measurement, climate change and anthropogenic activities are factors affecting the variations of wind speed. This could be the possible reason for increasing trend of wind speed observed in this study.

The monthly mean Weibull shape parameter, $\mathrm{k}$ ranges from 3.06 to 6.60 with an annual mean value of 4.66 (Table 1). The high value of $k$ is an indication of data spread in the normal distribution and good uniformity with relatively small scatter exhibited by the data spread. The scale parameter could be related to the mean wind speed

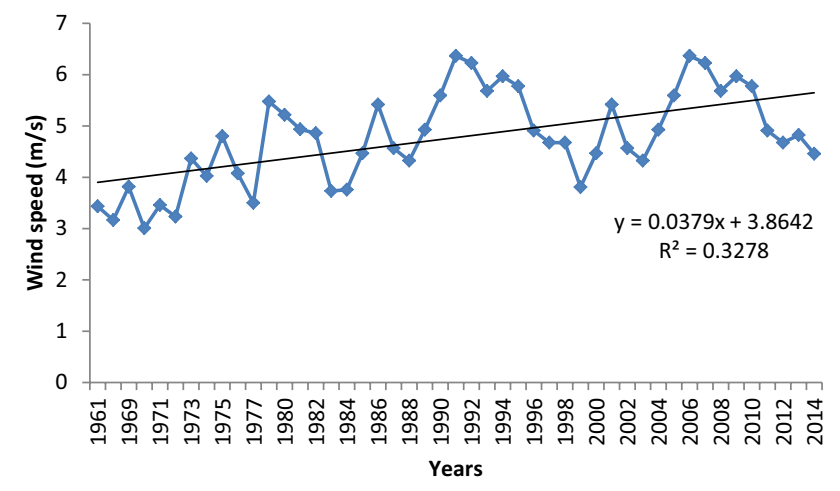

Fig. 2 Variation trend of annual mean wind speed in Makurdi (1961-2014)

through the shape parameter, which determines the uniformity of the wind speeds in a given site [6]. Hence, the $k$ value is necessary for certifying the probability of observing winds speed. From April through August, it could be observed that as the wind speeds tend to cluster towards a certain mean wind speed of $5.09 \mathrm{~ms}^{-1}$, the value of $\mathrm{k}$ increased from 4.01 to 6.60 . This could be due to the fact that when the wind regime is clustered to a certain mean value, $\mathrm{k}$ increases [4].

On the other hand, the monthly mean Weibull scale parameter, c ranges from 3.86 to $6.48 \mathrm{~ms}^{-1}$ with an annual mean value of $5.23 \mathrm{~ms}^{-1}$. The scale parameter, $\mathrm{c}$ is the value of the wind speed predicted using the values of the Weibull shape parameter, $k$. An area with high value of $c$ is an indication of the windy nature of the location [4]. It is worthy to note that the maximum value of $\mathrm{c}\left(6.48 \mathrm{~ms}^{-1}\right)$ was observed in April. This corresponds to the maximum mean wind speed $\left(5.88 \mathrm{~ms}^{-1}\right)$, while the minimum value of c $\left(3.86 \mathrm{~ms}^{-1}\right)$ was observed in November and this corresponds to the minimum mean wind speed $(3.52 \mathrm{~m} / \mathrm{s})$.
Table 1 Monthly mean wind speed characteristic and energy potential in Makurdi (1961-2014)

\begin{tabular}{lllllllll}
\hline Month & $V_{m}(\mathrm{~m} / \mathrm{s})$ & $\mathrm{SD}$ & $\mathrm{k}$ & $\mathrm{c}(\mathrm{m} / \mathrm{s})$ & $\mathrm{V}_{\mathrm{F}}(\mathrm{m} / \mathrm{s})$ & $\mathrm{V}_{\mathrm{E}}(\mathrm{m} / \mathrm{s})$ & $\mathrm{P}_{\mathrm{D}}\left(\mathrm{W} / \mathrm{m}^{2}\right)$ & $\mathrm{E}_{\mathrm{D}}\left(\mathrm{kWh} / \mathrm{m}^{2}\right)$ \\
\hline Jan & 5.24 & 1.87 & 3.06 & 5.86 & 5.15 & 6.91 & 122.34 & 88.08 \\
Feb & 5.48 & 1.75 & 3.45 & 6.10 & 5.52 & 6.96 & 132.04 & 95.07 \\
March & 5.81 & 1.40 & 4.67 & 6.35 & 6.03 & 6.85 & 140.80 & 101.38 \\
April & 5.88 & 1.64 & 4.01 & 6.48 & 6.04 & 7.17 & 153.39 & 110.44 \\
May & 4.96 & 1.32 & 4.22 & 5.45 & 5.11 & 5.97 & 90.31 & 65.02 \\
June & 4.84 & 1.13 & 4.85 & 5.28 & 5.03 & 5.67 & 80.64 & 58.06 \\
July & 4.97 & 1.05 & 5.42 & 5.39 & 5.19 & 5.71 & 85.38 & 61.47 \\
Aug & 4.80 & 0.85 & 6.60 & 5.15 & 5.02 & 5.36 & 74.14 & 53.38 \\
Sept & 4.09 & 0.82 & 5.73 & 4.42 & 4.27 & 4.65 & 46.80 & 33.70 \\
Oct & 3.59 & 0.77 & 5.33 & 3.89 & 3.74 & 4.13 & 32.15 & 23.15 \\
Nov & 3.52 & 0.92 & 4.29 & 3.86 & 3.63 & 4.22 & 32.10 & 23.11 \\
Dec & 4.13 & 1.09 & 4.27 & 4.54 & 4.27 & 4.97 & 52.11 & 37.52 \\
Annual & 4.77 & 1.22 & 4.66 & 5.23 & 4.97 & 5.65 & 86.85 & 62.53 \\
\hline
\end{tabular}


The monthly mean most probable wind speed, $V_{F}$ ranges from 3.63 to $6.04 \mathrm{~ms}^{-1}$ with an annual mean value of $4.97 \mathrm{~ms}^{-1}$ (Table 1). Similarly, the annual mean wind speed carrying maximum energy, $V_{E}$ was $5.65 \mathrm{~m} / \mathrm{s}$. It is usually greater than the wind speed. From this study, the observed annual mean wind speed was $4.77 \mathrm{~m} / \mathrm{s}$ which is less than the observed wind speed carrying maximum energy $(5.65 \mathrm{~m} / \mathrm{s})$. In the estimation of wind turbine design or rated wind speed, wind speed carrying maximum energy is very essential. Wind turbine system has been reported to operate efficiently at its rated wind speed. Therefore, it is required that the rated wind speed and the wind speed carrying maximum energy should be as close as possible [6]. Therefore, for this site, a wind turbine of rated wind speed $3.5 \leq \mathrm{V} \leq 5.5 \mathrm{~m} / \mathrm{s}$ is recommended.

Monthly mean wind power, $P_{D}$ and energy densities, $E_{D}$ vary proportionally to the monthly mean wind speed (Table 1). This is because of the dependence of wind power and energy on the wind speed. Thus, there is a correlating maximum wind power and energy density in April with the minimum in November correspond to the mean wind speed. The peak power and energy densities are $153.39 \mathrm{~W} /$ $\mathrm{m}^{2}$ and $110.44 \mathrm{kWh} / \mathrm{m}^{2}$ while the least are $32.10 \mathrm{~W} / \mathrm{m}^{2}$ and $23.11 \mathrm{kWh} / \mathrm{m}^{2}$ respectively. The annual mean wind power and energy densities observed in this study are $86.85 \mathrm{~W} /$ $\mathrm{m}^{2}$ and $62.53 \mathrm{kWh} / \mathrm{m}^{2}$ respectively (Table 1 ). Wind power density directly determines electric power efficiency in using wind energy in the sense that the higher the density, the higher the electric power generating potential of the site. This suggests that, Makurdi has a good prospect for wind energy resource.

It is interesting to note that the results of wind speed characteristics, Weibull shape parameter, scale parameter, wind power and energy densities observed in this study is in line with the results of other researchers (e.g. [23-25]). The slight variations in the results may be due to the prevailing wind data of the study area; since wind speed which is the major input parameter in the analysis varies from one location to another.

Pacific Northwest National Laboratory (PNL) wind power classification scheme was used to classify the wind speed in Makurdi [26]. Based on this classification scheme, the monthly mean power density in Makurdi mostly falls into class $1\left(P_{D} \leq 100\right)$ except in January, February and March, when it falls into class $2\left(100<P_{D} \leq 150\right)$. In April, it falls into class $3\left(150<P_{D} \leq 200\right)$. However, the annual mean power density for Makurdi is $86.85 \mathrm{~W} / \mathrm{m}^{2}$. Thus, the monthly mean power density falls into class 1 wind resource category $\left(P_{D} \leq 100\right)$

Generally, wind profile for Makurdi shows that it falls into a moderate wind prospect zone of Nigeria, having mean wind speed which is more than the cut-in wind speed $(3.0-4.0 \mathrm{~m} / \mathrm{s})$ required for most wind turbine generators to operate [11].

\section{Conclusions}

1. The monthly mean wind speed varies between $3.51 \mathrm{~m} / \mathrm{s}$ in November and $5.87 \mathrm{~m} / \mathrm{s}$ in April.

2. The annual mean wind speed characteristics (mean wind speed, most probable wind speed, and wind speed carrying maximum energy) are $4.77,4.97$ and $5.65 \mathrm{~m} / \mathrm{s}$ respectively.

3. The annual mean Weibull shape parameter, $\mathrm{k}$ was 4.66 , while the annual mean of the Weibull scale parameter, c was $5.23 \mathrm{~m} / \mathrm{s}$.

4. The annual mean power and energy densities were $86.85 \mathrm{~W} / \mathrm{m}^{2}$ and $62.53 \mathrm{kWh} / \mathrm{m}^{2}$ respectively.

5. Based on the wind data used in this study, the wind energy resource in Makurdi from the PNL classification may be classified into class 1 .

6. The wind speed for Makurdi has satisfied the range $(3.0-4.0 \mathrm{~m} / \mathrm{s})$ recommended for most turbines to start generating electricity. Hence, Makurdi and its environs have great prospect for wind power generation.

Acknowledgements The authors thank the Nigeria Meteorological (NIMET) Agency, for providing the wind speed data used in this research work.

Funding The authors declare that there is no funding for this study.

\section{Compliance with ethical standards}

Conflict of interest The authors declare that they have no conflict of interest.

\section{References}

1. Idris NA, Lamin HS, Ladan MJ, Yusuf BH (2012) Nigeria's wind energy potentials: the path to a diversified electricity generation-mix. Int J Mod Eng Res 2(4):2434-2437

2. Ajayi OO, Fagbenle RO, Katende J, Aasa SA, Okeniyi JO (2013) Wind profile characteristics and turbine performance analysis in Kano, north-western Nigeria. Int J Energy Environ 4:1-15

3. Ajay $\mathrm{OO}$ (2010) Availability of wind energy resource potential for power generation of Jos, Nigeria. Wind Eng 34(3):303-312

4. Uquetan UI, Egor AO, Osang JE, Emeruwa C (2015) Empirical study of wind energy potential in Calabar, Cross River State Nigeria. Int J Technol Res 4(10):113-121

5. Dokur E, Kurban M (2015) Wind energy potential analysis based on Weibull distribution. Balkan J Electr Comput Eng 3(4):231-235

6. Oyedepo SO, Adaramola MS (2012) Analysis of wind speed data and wind energy potential in three selected locations in southeast Nigeria. Int J Energy Environ 3(7):1-11 
7. Youm I, Sarr J, Sall M, Ndiaye A, Kane MM (2005) Analysis of wind data and wind energy potential along the northern coast of Senegal. Rev Energy Renew 8:95-108

8. Ayoola TB, Ahmed S, Samuel S, Isa KO (2017) Sustainable energy development in Nigeria: wind, hydropower, geothermal and nuclear. Renew Sustain Energy Rev 74:474-490

9. Erik LP (2017) In search of the wind energy potential. J Renew Sustain Energy 9:052301

10. Samira K, Amar R, Daoud AK (2017) The sustainable worldwide offshore wind energy potential: a systematic review. J Renew Sustain Energy 9:065902

11. Agbetuyi AF, Akinbulire TO, Abdulkareem A, Awosope COA (2012) Wind energy potential in Nigeria. Int Electr Eng J 3(1):595-601

12. Ajayi OO, Fagbenle RO, Katende J, Ndambuki JM, Omole DO, Badejo AA (2014) Wind energy study and energy cost of wind electricity generation in Nigeria: past and recent results and a case study for south west Nigeria. Energies 7(1):8508-8534

13. Anyanwa EE, Iwuagwu CJ (1995) Wind characteristics and energy potentials for Owerri Nigeria. Renew Energy 6:125-128

14. Asiegbu AD, Iwuoha GS (2007) Studies of wind resources in Umudike, south east Nigeria-an assessment of economic viability. J Eng Appl Sci 2:1539-1541

15. Nze-Esiaga N, Okoghue EC (2014) Assessment of wind energy potential as a power generation source in five locations of South Western Nigeria. J Power Energy Eng 2:1-13

16. Fagbenle RO, Katende J, Ajayi OO, Okeniyi JO (2011) Assessment of wind energy potential of two sites in north-east Nigeria. Renew Energy 36:1277-1293

17. Ohijeagbon OD, Ajayi OO (2014) Potential and economic viability of stand-alone hybrid systems for a rural community of Sokoto, north-west Nigeria. Front Energy 8:145-159
18. Ajayi OO, Fagbenle RO, katende J, Okeniyi JO (2011) Availability of wind energy resource potential for power generation of Jos, Nigeria. Front Energy 5:376-385

19. Ahmed A, El-Suleiman A, Nasir A (2013) An assessment of wind energy resource in north central Nigeria, Plateau. Sci J Energy Eng 1:13-17

20. Ikwuba A (2011) Absolute poverty deterioration in Benue State: rural people oriented coping strategy. Cross Cult Commun 7(1):132-140

21. Johnson OM, Jennifer NA (2017) Temperature variability, intensity of wind speed and visibility during harmattan in Makurdi town, Nigeria. JORIND 15(1):198-206

22. Amadi SO, Udo SO (2014) A study of trends and variations of monthly mean wind speed data in Nigeria. Imperial Int J Appl Phys 5(14):1-12

23. Al-Buhairi MH, Al-Haydari A (2012) Monthly and seasonal investigation of wind characteristics and assessment of wind energy potential in Al-Mokha, Yemen. Energy Power Eng 4:125-131

24. Khouloud B, Mahieddine A, Rabah L (2016) Assessment and analysis of wind energy generation and power control of wind turbine system. Rev Sci Technol Synth 32:147-162

25. Udo NA, Oluleye A, Ishola KA (2017) Investigation of wind power potential over some selected coastal cities in Nigeria. Innov Energy Res 6:156-162

26. Ilinca A, McCarthy E, Chaumel JL, Retiveau JL (2003) Wind potential assessment of Quebec Province. Renew Energy 28:1881-1897 